\title{
Comparison of Sports Anxiety in three different Stages between Team and Individual Players
}

\author{
Dr. Th. Shyam Singh ${ }^{1}$ Dr. N. Sunderlal Singh ${ }^{2}$ Dr. S. Ranjit Singh ${ }^{3}$ \\ ${ }^{I}$ Assistant Professor, Department of Physical Education, Health Education \& Sports, D.M. College of Science, \\ Imphal, Manipur. \\ ${ }^{2}$ Assistant Professor, Faculty of Physical Education \& Sports, D.M. College of Commerce, Imphal, Manipur. \\ ${ }^{3}$ Associate Professor, Department of Physical Education, Health Education \& Sports, D.M. College of Science, \\ Imphal, Manipur.
}

\begin{abstract}
To find out the degrees of anxieties experienced by both the individual and team sports persons of Manipur at three different stages of sports such as prior to the actual play, during the progress of the play and after the conclusion of the play over the period of five years beginning from 1995 to 2000 A.D. The researchers mainly adopted the simple and easy methods of questionnaires, personal visits to national and state level sportspersons of Manipur at their residence, hostels and other sports complexes. The subjects of the study were 173 teams' sportspersons and 173 individual sportspersons of Manipur over the span of five years starting form 1995 to 2000. The team sports persons were form the field of hockey, handball, kabaddi, sepak-takraw and volleyball, on the other hand the individual team sportspersons were from the disciplines of Archery, cycling, table-tennis, wrestling, fencing, athletics, weight lifting, judo, boxing and tae-kwondo respectively. Data were collected by using "Anxiety test questionnaire" tools.

Comparing the sport anxiety before, during and after the play, both the individual and team sportsperson were found significantly higher in anxiety level during the play than the before and after the play situation. The sports anxiety between the individuals and teams sports found no significant difference before the play and after the play. But there is significant different found during the play i.e., individuals sportspersons were found significantly higher in sports anxiety then the team sportspersons.
\end{abstract}

Key wards: Sports anxiety, individual and team sportspersons, STAI Form Y-I, comparative t test.

\section{Introduction:}

Sports play a vital role in our society. The theme of being is animated by the different colours of sports. The foetus of human stigmas is thus purged away with the flairs of sports. The excitements generated by the potentials of sports are so great that even the bed-ridden patients incline to jump up from their bets of fate. Momentarily, sports often give the soothing touch of healing to the morlorn hearts of the society. Amongst the various factors of human traits and legacies sports is regarded one of the most important legacies towards human development. With this legacy human society is forging ahead with fast strides. Although there is no finishing line for this race of development there is certainly a line for betterment of sports vicinity.

The history of sports at Manipur, unlike some states of India, is quite clear and transparent. The traces of sports can be easily seen with the chronicles of Manipur history. There were many games and sports which wee wide prevalent among the general public of Manipur since the beginning of the Christian era. There are games and sports at Manipur which are quite unique in character. It is also believed that the game of polo had its origin at Manipur. Some renounce games and sports of the world have similar styles and form with that of the primitive games and sports of Manipur. It may be due to the p0roliferation of history or it may be because of the nomadic influence with due course of time. The games like wrestling, tug-of -war, rugby etc. have been played by and large by the inhabitant of Manipur since time in immemorial. There are also certain games of Manipur which have very similar forms with the renounce games of the either than those which have been stated earlier. Such games are that of Manipuri martial arts, Manipuri hockey and Manipuri chess commonly known as "Kei-Yen" and "Machin-Manao". People of Manipur have always devoted their lives for bringing more and more laurels for the nation and it has been shown with the sports records of Manipur. The feeling of happiness and contentment lies in the various degrees of anxiety. Anxiety plays the greatest role in the sports arena. It is this anxiety which people regard as the important factor of sports excitement without anxiety the taste of sports are liable to be lost in the thin air. Only anxiety can preserve the taste of sports. The cause of anxiety is varied in nature. It may come from incompetency, new exposures, frustrations, happiness etc. all these causes are again different in amplitude. The anxiety level caused by new exposures is comparatively low in comparison with the other causes. The most severe form of anxiety may be due to in competency and frustration. Happiness on the other hand slightly boosts up the anxiety level on the positive side of sports aspect but it may not be always true. 
The individual and team sports persons may have different amplitudes of anxiety. Nobody is without anxiety in the field of games and sports. It is this important factor which affects the performance of sports persons in their understandings and challenges at sports. Anxiety may be reduced or it may be increased with circumstances. Anxiety is a state of mind where the reaction of the person concerned to the set of problems or tasks do tend to respond with a different attitude rather than the persons usual form of response. Anxiety, thus, tends a person to respond with the problem with a lesser capability. It is sort of worryness or nervousness about the events, their occurrences and consequences. The degree of anxiety is different from person to person. A person with higher proficiency has the lesser degree of anxiety than a person of low proficiency for sort; it can be assumed that anxiety has a correlation with confidence. Lack of confidence naturally tends to increase the amplitude of anxiety for every person. The degree of anxiety differs from situation to situation, where the nervous felt before the actual task begin and the nervousness felt during the task is on and after the competition of the task do have a wide difference. This anxiety is again depends on the person so concerned.

Anxiety can be either somatic or cognitive in nature. The symptoms of somatic anxiety comprises of mental worries, fears, nervousness and diffidence. The set of mind is disturbed by anxiety and destroys the equilibrium of confidence. A person is thus, put into an emotional situation. The greater the disturbance the greater the diffidence is. Anxiety, thus, plays a very crucial and emotional role in everyone's life. On the other hand anxiety may root-up the potentials of certain people. This force of anxiety which people generally called as the negative motivator of anxiety usually interferes with the productive thinking of people. Anxiety changes the metabolism of human mind and body. Whenever people get anxious his rate of heart beat increases. The functions of other organs of his body also change. His breathing becomes more rapid and the consumption of oxygen increases. It also further raises the blood pressure. Human behavior is suddenly changed with sudden experience of anxiety. It sometimes causes a person to tremble slightly, to engage with nervous activities like wriggling legs and stirring at objects with fixed eyes. The most severe form of anxiety is insomnia, the state of sleeplessness, and restlessness. Anxiety plays a paramount role in sport. It is the challenge to sports participation which produces anxiety. How and athlete handles the anxiety determines how successful he would be. The degree of anxiety also varies with a number of different conditions. Anxiety is likely to be greater in higher competitive sports than in relatively non-competitive sports, because in the competitive sports, participants are expected to win and great demands are made upon them to succeed. The study of the effect of anxiety on sports performance has become a major topic of interest to sports psychologists in recent years. The degree of perceived anxieties is and important variable to be considered in the performance of and individual.

The biggest obstacle often felt by the spots persons in the world of games and sports is that of anxiety. In Manipur the sports persons are often hit with the blows of anxiety. It is felt by each and everyone. Prior to the actual competition begins the sportspersons are often strangulated with over anxiousness. But it slowly decreases the tenseness with the actual challenges are on. During the challenge the tenseness slackness and it ceases at the end of the challenge. This phenomenon persists for almost all the sports persons of Manipur. The scenario may have a different picture with certain exceptions. At the conclusion of every games and sports the anxiety level reduces at almost the minimum. But this may not happen on every occasion, as the conclusion of a challenge may be the begging of another challenge. The extra punitive behavior experienced by both the individual and team sportspersons of Manipur requires careful observation in order to relinquish its severity. Individuals' aggressiveness is often referred to as intropunitive behaviors. All these aspects are grounds of victory and failure. There may be some games and sports where the players are encouraged to adopt aggressive behaviors. But there are also certain games and sports where the behavior requires being at levity. It is quite difficult to state whether the individual players and the team players have similar degree of anxiety. This aspect of behavior may be ascertained to the most satisfaction of direct discussion and inquiry. Certain theories do exist for the task. The present study also looks forward to these accepted tools and methods for the end of analysis. The researcher had been drawn towards this aspect of sports and this inevitably lead him to the present work of research, some types of questionnaires are apparent for the work. The individual sportspersons are targeted to give their reactions and opinions with the set of a questionnaire. It may be easier or the individuals to give their responses singularly than the team sports persons collectively. As the team sportspersons are comprised of individual. The teams tend to have varies responses rather than unified versions. But it is not impossible to acquire the required query despite of fluctuations. The saying that the majority carry the vote always hold good. The yearning to win in games and sports always prevails in the orbit of sports. In Manipur, too, the sports persons are exposed to this orbit of sports like the other states. The aspiration of winning has been always checked by the powerful force in the guise of anxiety. The study may be of a great value foe purging the state of anxiety and thus enhance the stability of sports potentials by and large.

The study has been confined to only five years, beginning from 1995 to 2000 . The span of study period has been thus limited with the hope of arriving at the best conclusion.

Statement of the problem: The purpose of the study was to find out the degrees of anxieties experienced by both the individual and team sports persons of Manipur at three different stages of sports such as prior to the 
actual play, during the progress of the play and after the conclusion of the play over the period of five years beginning from 1995 to 2000 A.D.

Method: Under the longitudinal research the researchers mainly adopted the simple and easy methods of questionnaires, personal visits to national and state level sportspersons of Manipur at their residence, hostels and other sports complexes. The subjects of the study were 173 teams' sportspersons and 173 individual sportspersons of Manipur over the span of five years starting form 1995 to 2000. The team sports persons were form the field of hockey, handball, kabaddi, sepak-takraw and volleyball, on the other hand the individual team sportspersons were from the disciplines of Archery, cycling, table-tennis, wrestling, fencing, athletics, weight lifting, judo, boxing and tae-kwondo respectively. Data were collected by using "Anxiety test questionnaire" tools which is developed by Charles D. Spielberger. The marks were calculated by using "STAI Form Y-I" scoring key method. To find out the significance difference in anxiety level "t-test" were calculated in 0.05 and 0.01 confidence level.

\section{Result of the Study:}

Researcher selected and identified appropriate raw data group wise. Mean score, Standard Deviation of each group was calculated. After Calculating the Mean, Standard Deviation the researcher applied ' $t$ ' test. The mean score of sports anxiety for individual and team sports players were compared in three situation, i.e., before, during and after the competition.

Comparison of sports anxiety for the individual team sportspersons before, during and after the play:

Table 1 shows that the calculated ' $t$ ' value 9.53 is greater than the table value 1.96 , the individual team sportspersons sport anxiety level before the play and during the play was highly significant at .05 confidence level

Table 1: Comparative anxiety before and during the play for individuals' sportspersons:

\begin{tabular}{|l|l|l|l|l|l|}
\hline Category & Mean & SD & Mean difference & 'r' & ' $\mathrm{t}$ ' \\
\cline { 1 - 5 } Before play & 80.54 & 15.24 & 4.75 & 0.59 & 9.53 \\
\hline During play & 85.29 & 12.03 & & & \\
\hline
\end{tabular}

Significant at .05 level of confidence, $\mathrm{t}_{05}(344)=1.96$

Table 2 shows that the calculated ' $t$ ' value 5.89 is greater than the table value 1.96 , the individual team sportspersons sport anxiety level after the play and during the play was highly significant at .05 confidence level.

Table 2: Comparative anxiety during and after the play for individuals' sportspersons:

\begin{tabular}{|l|l|l|l|l|l|}
\hline Category & Mean & SD & Mean difference & 'r' & 't' \\
\hline After play & 72.99 & 13.70 & 12.30 & 0.41 & 5.89 \\
\hline During play & 85.29 & 12.03 & & & \\
\hline
\end{tabular}

Significant at .05 level of confidence, $\mathrm{t}_{.05}(344)=1.96$

Table 3 below shows that the calculated ' $t$ ' value 12.89 is greater than the table value 1.96 , the individual team sportspersons sport anxiety level before and after the play was highly significant at .05 confidence level.

Table 3: Comparative anxiety before and after the play for individuals' sportspersons:

\begin{tabular}{|l|l|l|l|l|l|}
\hline Category & Mean & SD & Mean difference & 'r' & 't' \\
\cline { 1 - 5 } Before play & 80.54 & 15.24 & 7.55 & 0.70 & 12.89 \\
\hline After play & 72.99 & 13.70 & & & \\
\hline
\end{tabular}

Significant at .05 level of confidence, $\mathrm{t}_{.05}(344)=1.96$

Comparison of sports anxiety for the team sportspersons before, during and after the play:

Table 4 below shows that the calculated ' $t$ ' value 8.22 is greater than the table value 1.96 , the team sportspersons sport anxiety level before and during the play was highly significant at .05 confidence level.

Table 4: Comparative anxiety before and during the play for teams' sportspersons:

\begin{tabular}{|l|l|l|l|l|l|}
\hline Category & Mean & SD & Mean difference & 'r' & 't' \\
\cline { 1 - 4 } Before play & 79.15 & 16.30 & 4.05 & 0.56 & 8.22 \\
\hline During play & 83.19 & 15.07 & & & \\
\hline
\end{tabular}

Significant at .05 level of confidence, $\mathrm{t}_{.05}(344)=1.96$

Table 5 below shows that the calculated 't' value 5.54 is greater than the table value 1.96, the team sportspersons sport anxiety level after the play and during the play was highly significant at .05 confidence level.

Table 5: Comparative anxiety after and during the play for teams' sportspersons:

\begin{tabular}{|l|l|l|l|l|l|}
\hline Category & Mean & SD & Mean difference & 'r' & ' $\mathrm{t}$ ' \\
\cline { 1 - 5 } After play & 67.47 & 14.75 & 15.72 & 0.39 & 5.54 \\
\hline During play & 83.19 & 15.07 & & & \\
\hline
\end{tabular}

Significant at .05 level of confidence, $\mathrm{t}_{05}(344)=1.96$

Table 6 below shows that the calculated ' $t$ ' value 5.34 is greater than the table value 1.96 , the team sportspersons sport anxiety level before and after the play was highly significant at .05 confidence level. 
Table 6: Comparative anxiety before and after the play for teams' sportspersons:

\begin{tabular}{|l|l|l|l|l|l|}
\hline Category & Mean & SD & Mean difference & 'r' & ' $\mathrm{r}$ ' \\
\hline Before play & 79.15 & 16.30 & 11.68 & 0.38 & 5.34 \\
\hline After play & 67.47 & 14.75 & & & \\
\hline
\end{tabular}

Significant at .05 level of confidence, $\mathrm{t}_{.05}(344)=1.96$

Comparison of sports anxiety between individuals and teams sports before, during and after the play:

Table 7 below shows that the individual and team sports persons were having no significant difference in sport anxiety before the play since the calculated ' $t$ ' value 1.42 is smaller than the table value 1.96 , the team and individual sportspersons sport anxiety level before the play was found no significant at .05 confidence level.

Table 7: Comparative anxiety between the individual and team sportspersons before the actual play took place:

\begin{tabular}{|l|l|l|l|l|l|}
\hline $\begin{array}{l}\text { Category (before } \\
\text { play) }\end{array}$ & Mean & SD & Mean difference & 'r' & \\
\hline Individual & 80.54 & 15.24 & 1.39 & 0.11 & 1.42 \\
\hline Team & 79.15 & 16.03 & & & \\
\hline
\end{tabular}

Significant at .05 level of confidence, $\mathrm{t}_{.05}(344)=1.96$

Table 8 below shows that the individual and team sports persons were having significant difference in sport anxiety test during the play since the calculated ' $t$ ' value 2.95 is greater than the table value 1.96 , the individual sportspersons were found more sport anxiety level than the team sportsperson during the play at .05 confidence level.

Table 8: Comparative anxiety between the individual and team sportspersons during the process of game:

\begin{tabular}{|l|l|l|l|l|l|}
\hline $\begin{array}{l}\text { Category (during } \\
\text { play) }\end{array}$ & Mean & SD & Mean difference & 'r' & \\
\hline Individual & 85.29 & 12.03 & 2.10 & 0.22 & 2.95 \\
\hline Team & 83.19 & 15.07 & & & \\
\hline
\end{tabular}

Significant at .05 level of confidence, $\mathrm{t}_{.05}(344)=1.96$

Table 9 below shows that the individual and team sports persons were having no significant difference in sport anxiety after the play since the calculated ' $t$ ' value .11 is smaller than the table value 1.96 , the team and individual sportspersons sport anxiety level after the play was found no significant at .05 confidence level.

Table 9: Comparative anxiety between the individual and team sportspersons at the ends of the game:

\begin{tabular}{|l|l|l|l|l|l|}
\hline $\begin{array}{l}\text { Category (after } \\
\text { play) }\end{array}$ & Mean & SD & Mean difference & 'r' & ' $\mathrm{l}$ ' \\
\cline { 1 - 5 } Individual & 72.99 & 13.70 & 5.52 & 0.01 & 0.11 \\
\cline { 1 - 3 } Team & 67.47 & 14.75 & & & \\
\hline
\end{tabular}

Significant at .05 level of confidence, $\mathrm{t}_{.05}(344)=1.96$

Table 10 below shows that the individual and team sports persons were having significant difference in total sport anxiety test since the calculated ' $t$ ' value 2.22 is greater than the table value 1.96 , the individual sportspersons were found more sport anxiety level than the team sportsperson at .05 confidence level.

Table 10: Total comparative anxiety between the individual and team sportspersons:

\begin{tabular}{|l|l|l|l|l|l|}
\hline $\begin{array}{l}\text { Category ' } \\
\text { score) }\end{array}$ & SD' & Mean difference & ' & \\
\hline Individual & 238.82 & 34.75 & 9.00 & 0.17 & 2.22 \\
\hline Team & 229.82 & 36.38 & & \\
\hline
\end{tabular}

Significant at .05 level of confidence, $\mathrm{t}_{.05}(344)=1.96$

\section{Discussion:}

While comparing the sport anxiety before, during and after the play, both the individual and team sportsperson were found significantly higher in anxiety level during the play than the before and after the play situation. While comparing before and after the play, sport anxiety level was also significantly higher before the play than after the play. It shows more anxiety during the play and before the play than after the play.

In comparing the sports anxiety between the individuals and teams sports, there is no significant difference found before the play and after the play. But there is significant different found during the play, individuals sportspersons were found significantly higher in sports anxiety then the team sportspersons. If we compare to total score Individual sportsperson were having higher anxious level then the team sportsperson.

\section{References:}

[1]. Delip K Dureha, "Relationship between Achievement Motivation and Pre-competition anxiety of Indian inter-university Hockey Players", Abstracts of international conference on health sport and physical fitness-need for an integrated approach (Hissar: CCS Haryana Agricultural University January 16-18, 1995)

[2]. Phairembam Jiteshwor, N. Sunderlal, S. Ranji, Hassan gharayagh zandi and N. Jinet, "Comparative study of the Sports Achievement Motivation between Male and Female School Basketball Players", IOSR Journal Of Humanities And Social Science (IOSR-JHSS) Volume 7, Issue 2 (Jan. - Feb. 2013, pp 23-26

[3]. Bente kjoss Hansen, "Prediction of Sport competitive state anxiety among coaches \& athletes", Dissertation Abstracts international, 44:10, April, 1984.

[4]. M.L. Kamlesh, “Educational Sports Psychology”. ( New Delhi-Friends Publication, 2006). 
[5]. Robert Glyn C. “Achievement Motivation in sports”. Department of Physical Education.University of Iltinous.

[6]. C.P. Singh, M. Ahmed, and I. Hussain, "A Comparative Study of Sports Achievement Motivation between Male and Female Badminton Players"'Vyayam-Vidnyan, 43(3), 2010, pp.30-33.

[7]. Elliot and McGregor "Test anxiety and the hierarchical model of approach and avoidance achievement motivation". Journal of Personality and Social Psychology, 76, 1999, pp.628-644.

[8]. K. Kaur, N.P. Sharma and D.K Dureha."Relationship between Achievement Motivation and Pre-Competition Anxiety of Indian Inter University Hockey Players" Scientific Journal in Sports and Exercise,3(2), 2007, pp.24-26.

[9]. B.S. Thakur, and L. Mohan "Personality Traits, Anxiety and Achievement Motivation Level of Volleyball Players and NonSpotmen",Journal of Sports and Sports Sciences, 31(4),2008, pp.23-29.

[10]. Tammy A. Schilling. "Achievement motivation: Conceptions of ability, subjective experience, task choice, and performance". Canadian journal of sports Psychology, 91, 2001, pp.238-246. 